\title{
Effects of a Magnetic Field on the Machining Accuracy for the Electrochemical Drilling of Micro Holes
}

\author{
Changfu Zhang ${ }^{1,2, *}$, Pixian Zheng ${ }^{1,2}$, Ruoyun Liang ${ }^{1,2}$, Kang Yun ${ }^{1,2}$, Xinguang Jiang ${ }^{1,2}$, Zhenghu Yan ${ }^{1,2}$ \\ ${ }^{1}$ School of Mechatronics Engineering, Xi' an Technological University, Xi' an 710021, China \\ ${ }^{2}$ Shaanxi Key Laboratory of Non-Traditional Machining, Xi'an 710021, China \\ *E-mail: cfzhang@xatu.edu.cn
}

doi: $10.20964 / 2020.02 .10$

Received: 14 July 2019 / Accepted: 22 November 2019 / Published: 31 December 2019

\begin{abstract}
Micro electrochemical machining (micro-ECM) is a promising machining technology for microparts of difficult-to-cut metallic materials and has been used in the industries of aeronautics and astronautics, ordnance, precision devices, and so on. The machining accuracy of micro-ECM is difficult to improve, so a magnetic field is employed to assist with the electrochemical drilling of micro holes. First, micro electrochemical drilling experiments with and without a magnetic field and with different magnetic flux densities were carried out. Then, the effects of the magnetic field on the machining accuracy of micro electrochemical drilling were analyzed and discussed based on the experimental results. The results showed that an external magnetic field whose direction was perpendicular to the feed direction improved the machining accuracy of micro electrochemical drilling, and the machining accuracy was the best when the magnetic flux density was approximately $0.1 \mathrm{~T}$. This study can help to improve the machining accuracy of micro electrochemical drilling and accelerate further research on magneticfield-assisted micro-ECM technology.
\end{abstract}

Keywords: Difficult-to-cut metallic material; Micro electrochemical machining; Magnetic field; Magnetic flux density; Machining accuracy

\section{FULL TEXT}

(C) 2020 The Authors. Published by ESG (www.electrochemsci.org). This article is an open access article distributed under the terms and conditions of the Creative Commons Attribution license (http://creativecommons.org/licenses/by/4.0/). 